Freshwater Biology (2013) 58: 1539-1555.

Running head: Macroecology of community traits

\title{
A macroecological perspective of trait patterns in stream communities
}

\author{
Jani Heino ${ }^{1,2}$, Dénes Schmera ${ }^{3,4} \&$ Tibor Erös ${ }^{4}$ \\ ${ }^{1}$ Ecosystem Change Unit, Natural Environment Centre, Finnish Environment Institute, Oulu, Finland \\ ${ }^{2}$ Department of Biology, University of Oulu, Oulu, Finland \\ ${ }^{3}$ Section of Conservation Biology, University of Basel, Basel, Switzerland \\ ${ }^{4}$ Balaton Limnological Institute, Centre for Ecological Research, Hungarian Academy of Sciences, Tihany, \\ Hungary
}

Correspondence: jani.heino@environment.fi 


\section{Summary}

1. Disregarding few classical ideas, large-scale approaches to understand variation in community traits (i.e. the trait composition of an ecological community) across stream ecosystems are rather recent. Case studies and review papers show clear evidence for the usefulness of trait-based analyses in bioassessment, but how community traits vary along natural gradients at large scales has not yet been synthesised. Here, we attempt to fill this gap by providing a synthesis of trait patterns of stream communities from a macroecological perspective.

2. We argue that although both natural and anthropogenic filters shape community traits, examination of natural filters, including those acting at large-scales, should receive increasing attention. This is because it is inadequately known how natural environmental conditions filter species on the basis of their traits. Such knowledge is vital for reliably inferring anthropogenic impacts on stream communities and ecosystems.

3. We synthesise knowledge of two large-scale spatial patterns of stream communities: among drainage basins (i.e. geographic variation) and within drainage basins (i.e. longitudinal variation). We also examine the temporal dimension of community traits. Our review highlights clear evidence for large-scale influences on the trait composition in stream systems. For example, despite previous contentions that community traits should vary negligibly across large geographical gradients, there is actually clear geographical variation across near-pristine systems. Furthermore, in accordance with theory, community traits in actual data sets vary along the longitudinal gradient of stream systems.

4. We provide an overview of empirical and statistical approaches to understanding the trait composition of stream communities in macroecological studies and conclude that the methodology should be carefully considered in among-study comparisons, because contrasting results may reflect 
not only ecological differences but also differences in methodology among studies (e.g. choice of species traits, their quantification and analytical methods).

5. We conclude that the question of how the trait composition of stream communities varies along geographical and environmental gradients is far from settled. A challenge for large-scale stream ecology is to provide a more specific view of trait variation in multiple taxonomic groups (e.g. do traits vary similarly in different organisms groups?), along major environmental gradients (e.g. is trait variation similar along the same environmental gradients in different regions?) and among different regional entities (e.g. do the traits vary, on average, among different regions?). 


\section{Introduction}

The field of macroecology has expanded rapidly recently. However, most macroecological studies to date have considered terrestrial organisms (Gaston \& Blackburn, 2000; Blackburn \& Gaston, 2006), and only recently has there been increasing interest in macroecological approaches in marine (e.g. Witman \& Roy, 2009) and freshwater systems (e.g. Hugueny et al., 2010). Disregarding some classical predictions (e.g. the river zonation (Illies \& Botosaneanu, 1963) or the river continuum concept (Vannote et al., 1980), large-scale approaches to understand community patterns in stream systems are rather recent (Olden et al., 2010; Verberk, van der Velde \& Esselink, 2010; Heino, 2011; Oberdorff et al., 2011). This is because stream ecology has been a small-scale science for a long time, with emphasis on species distribution patterns, community organisation and ecosystem processes at small spatial scales (e.g. Minshall, 1988; but see Minshall et al., 1983; Corkum \& Ciborowski, 1988). This adherence to studies at small scales has undoubtedly been important in advancing our understanding of species interactions, trophic cascades and ecological stoichiometry to name a few important topics (e.g. Allan \& Castillo, 2007). However, it is also important to understand patterns and processes associated with large-scale phenomena across stream ecosystems. It is thus obvious that the macroecological approach is important in the context of stream ecosystems. On the other hand, stream systems are also important for the advancement of macroecological research. Given that lotic systems differ in many fundamental respects from terrestrial, marine and lentic systems (e.g. unidirectional flow of stream water, high spatial and temporal variation in environmental conditions), also ecological patterns and their mechanistic basis could be expected to differ among these main realms. However, it may be that some general, recurring patterns emerge among the realms, providing support for some general laws underlying the distribution of life across the Earth. 
Understanding the structure and functioning of ecological systems benefits strongly from approaches utilising organisms' traits. These advantages include, for example, that evolutionarily distinct systems can be compared more easily based on organisms' traits than taxonomic approaches (i.e. regional species pools differ in species composition, but species are likely to share similar traits in different regions), and that the mechanistic bases underlying ecological patterns can be more directly chased (Southwood, 1977; Poff, 1997). Ecological research on organisms" traits has, therefore, increased rapidly during the last decades, and "trait" is a common buzzword in contemporary studies on evolutionary ecology, community ecology and macroecology. Being more than a simple buzzword, traits are often explicitly associated with approaches aiming at answering important questions about species-habitat relationships (e.g. Frimpong \& Angermeier, 2010), convergence of community structure among evolutionary distinct regions (e.g. Ernst et al., 2012), links between community structure and ecosystem functioning (e.g. Webb et al., 2010), and determinants of local abundance and regional distribution (e.g. Verberk et $a l ., 2010)$. In fact, understanding variation in species traits may provide a means for greater generalization in ecological research (e.g. McGill et al., 2006) and render community-based studies a more predictive science (e.g. Verberk et al., 2008).

The aim of the present article is to review the use of organisms' traits in community ecology, macroecology and biogeography with regard to stream systems. Our emphasis is dictated by the fact that these systems have been studied from the trait perspective intensively in the last few decades (Poff, 1997; Pont et al., 2006; Frimpong \& Angermeier, 2010). Although the intensive research has also led to a few general reviews on organisms' traits, these former reviews have mostly dealt with applied topics (Bonada et al., 2006; Statzner \& Beche, 2010) or have been largely restricted to macroinvertebrates (Verberk et al., 2008, Menezes et al., 2010). Our aim is, by contrast, to review literature on traits from theoretical and empirical studies that have dealt mostly with fundamental questions, whereas we will deal bioassessment issues in passing only. We extend 
on the habitat templets theory (Southwood, 1977; Townsend \& Hildrew, 1994) and, in particular, its core part of the species traits-environmental filters approach (Poff, 1997; Statzner, Hildrew \& Resh, 2001). Our review thus deals with large-scale variation in organisms' traits across sets of ecological communities at the biogeographic realm, ecoregion and catchment extents. Our aim is thus to show how community traits are related to major ecological gradients at large scales (Statzner et al., 2004; Heino et al., 2007; Poff et al., 2010). We will mostly deal with fish and macroinvertebrates due to the fact that these organisms have been studied most intensively using trait-based approaches.

\section{Natural versus anthropogenic filters}

An idea central to bioassessment using organisms' traits is that traits should vary very little across natural environmental gradients (Statzner et al., 2001). While some studies on stream fish have shown that natural landscape filters at various scales affect species traits in local communities (Angermeier \& Winston, 1999; Lamouroux et al., 2002; Hoeinghaus, et al., 2007; Pease et al., 2012), studies on stream macroinvertebrates have thus far suggested that trait patterns across local communities in little anthropogenically altered streams are relatively stable across Europe (Statzner et al., 2001, 2004; Statzner, Bonada \& Doledec, 2008), France (Charvet et al., 2000) and multiple smaller spatial extents (Doledec et al., 2000). As pointed out by Statzner et al. (2004), "these latter results are controversial to the idea that traits are filtered in a top-down way through multiple landscape filters". We see two potential reasons for these contrasting findings. First, most studies on fish are truly concerned with traits at the level of individual species, while most studies on macroinvertebrates have thus far considered genus and higher taxonomic levels. Second, there have been clear methodological differences between studies. The latter reason may also be related to some differing findings between studies on macroinvertebrates across little anthropogenically 
disturbed streams (e.g. compare Statzner et al., 2001 and Heino et al., 2007). Third, the set-up of the study may also influence the findings. If there are strong gradients in environmental conditions, one should assume that both taxonomic composition and traits vary strongly along natural ecological gradients (Logez et al., 2010; Poff et al., 2010).

A large number of studies on anthropogenically altered streams have shown that anthropogenic influences set a strong filter for organisms' traits (reviewed by Bonada et al., 2006; Statzner \& Beche, 2010). Although we by no means argue that anthropogenic filters do not control ecological communities, we intend to go one step back and summarise how natural gradients influence community traits. It is hypothesised that organisms have evolved mostly in response to natural environmental variation and they should possess traits that have helped them in persisting in natural environmental conditions (Poff \& Ward, 1990; Townsend \& Hildrew, 1994). In this respect, the evolutionary periods over which species have evolved in response to environmental conditions are much longer than the periods over which anthropogenic habitat alteration has occurred. Anthropogenically-modified ecosystems are, from evolutionary perspective, habitats with very specific and novel environmental conditions. These novel conditions allow the persistence of only such species that have evolved in similar natural environmental conditions or which show remarkable plasticity in traits. A recent study showed that the functional composition of stream fish responds more strongly to relatively small changes in natural environmental gradients (e.g. altitude, stream width) than to anthropogenic stress gradients (e.g. nutrient enrichment) (Erős et al., 2012). It follows that, although organisms' traits in ecological communities respond to both natural and anthropogenic environmental filters, interpretation of the responses of community traits to natural environmental gradients is highly important.

\section{Macroecological gradients across stream ecosystems}


Environmental conditions vary to some degree among stream ecosystems at the scales of biogeographic realms, biomes, ecoregions and drainage basins (Brown \& Lomolino, 1998; Bailey, 2010). For example, streams in different biomes typically deviate from each other in catchment vegetation (cf. temperate deciduous forest streams vs. temperate grassland streams; boreal coniferous forest streams vs. arctic tundra streams), which should affect both physical characteristics and resources available to organisms (Ross, 1963). Similarly, hydrologic regimes as related to rainfall are highly variable among such regional entities (Gasith \& Resh, 1999; Poff, 1996). Thus, if the environmental conditions differ consistently among streams of different biomes, then one would also expect to find differences in the species traits of local communities at the respective regional scales (Bonada, Doledec \& Statzner, 2007). Similarly, at smaller regional scales, including ecoregions and drainage basins, one could expect to find differences in community traits if the main underlying environmental templet differs among regions or if organisms respond differently to the same environmental gradient (see also Statzner et al., 2004). This latter response also pertains to community divergence among regions. The situation is likely to be more complex than this, however, and community convergence along major environmental gradients in different regions may also mean that the same trait combinations are selected in habitats with similar conditions in evolutionarily divergent biogeographic regions (Schluter, 1986; Lamouroux et al., 2002).

The match between species and environmental conditions through traits is at the heart of the concepts of the river continuum concept (Vannote et al., 1980), habitat templets (Southwood, 1977; Townsend \& Hildrew, 1994) and landscape filters (Tonn, 1990; Poff, 1997). For example, the concept of the landscape filters centres around the idea that environmental factors "filter" certain species traits from the regional pool at successive spatial levels from a drainage basin to a microhabitat, and this filtering process leads to the assembly of a local community. Within drainage 
basins, stream ecosystems range from small 1st order streams up to huge 12th order rivers. Along with changes in stream size, various physical factors vary along the river continuum, including depth, discharge and substratum characteristics. Such longitudinal changes alone represent much environmental variation of which organisms have to cope with. However, there is typically much variation in various environmental conditions among, say, neighbouring 1st order streams within a drainage basin, ranging from the degree of intermittency to differences in water chemistry (e.g. Allan \& Castillo, 2007). These multiple environmental factors make the question of environmental context in streams highly multidimensional. Such multidimensionality dictates that there are multiple opportunities for organisms to adapt and respond to various environmental conditions and, therefore, one could expect to find a close match between environmental conditions and species traits (see below).

Temporal variation can also be understood as a continuum of different scales, ranging from long evolutionary to very short periods of time. In evolutionary time, organisms adapt to the environmental conditions. In shorter periods of time, organisms respond to the varying environmental conditions by dynamic changes in distribution and abundance. Temporal variation can also be associated with present-day changes in environmental conditions (e.g. physical disturbances, chemical changes) that may lead to the extinction of species not possessing suitable traits to cope with changed environmental conditions (Townsend \& Hildrew, 1994). Southwood (1977) defined the temporal dimension as the degree of habitat durational stability, but also habitat predictability is important with regard to organisms' responses to habitat (Verberk et al., 2008). In stream systems, temporal variability may decrease from headwater streams to large rivers, which can be seen in factors such as relative variation in discharge (e.g. Hynes 1970). Thus, spatial and temporal variation (i.e. daily, monthly and yearly time scales) are often closely linked in stream ecosystems (e.g. Amoros \& Petts, 1993). While the spatial and temporal heterogeneity of the habitat template and the taxonomic responses of the biota have been relatively well explored especially in 
temperate regions, we argue that our knowledge is still inadequate of trait-based patterns across large spatial scales and various organism groups.

\section{Geographical variation in community traits}

Geographical analyses of variation in the species traits of ecological communities have been based on four major approaches (Table 1). Researchers have compared (1) watersheds (e.g. Mims et al., 2010) and (2) local communities (e.g. Bonada et al., 2007) among different regions, (3) contrasted variation along the same putatively important environmental gradients in different regions (e.g. Lamouroux et al., 2002) or (4) studied multiple environmental gradients across multiple regions (e.g. Heino, 2005). All these approaches have their strengths and limitations, with the first two focusing on overall differences, the third one on the degree of convergence along similar environmental gradients, and the fourth one on the multiple dimensions of the trait-environment and trait-space relationships across large geographical extents.

A few recent studies have examined differences in trait composition among river basins. For example, both Mims et al. (2010) and Jacquemin \& Pyron (2011) found differences in fish species traits across river basins in parts of North America. These differences were explained by glaciations during the Pleistocene, which resulted in northern areas being colonised from the southerly refugia after ice sheets receded. These southerly refugia presented a harsh environmental template for fish (e.g. variable habitat desiccation and hydrologic regimes) during glaciations, and these historical filters selected for traits that fit the opportunistic life history strategy (e.g. small size, short-lived, low age at maturity, small egg size, low fecundity; sensu Winemiller, 1992; Winemiller \& Rose, 1992). In general, there appears to be a latitudinal gradient, with small-bodied, short-lived species (i.e. opportunistic strategists) dominating at low latitudes and large-bodied, 
long-lived species (i.e. periodic equilibrium strategists) at high latitudes (Mims et al., 2010). Thus, historical filters (also pertaining to regional climatic regimes) must act together with ecological factors, which favour the periodic equilibrium strategy at high latitudes, generating present-day patterns in the trait composition of fish communities in North American watersheds.

Among-region variation in traits of local communities has been examined in a relatively few studies. Bonada et al. (2007) found both taxonomic (larger) and trait (smaller) composition and diversity differences between Mediterranean and temperate streams. For example, Mediterranean streams showed higher diversity, and their macroinvertebrates had traits enabling higher levels of dispersal and colonisation compared with temperate streams. Such traits (e.g. small size, aerial active dispersal) should be important in hydrologically highly variable Mediterranean streams, where dispersal and colonisation powers are important in countering local extinctions. By contrast, Schmera, Erös \& Heino (unpublished) found that both taxonomic and trait composition and diversity differed profoundly between three high-latitude drainage basins. They suggested that differences in environmental conditions of northern streams constitute strong species filters which vary among the drainage basins.

Studying stream fish from a traits perspective between Europe and North America, Lamouroux et al. (2002) found that trait proportions differed between continents and that up to 55 $\%$ of the variation in traits was related to continent. This was considered to be due to distinct evolutionary histories between the two continents. Lamouroux et al. (2002) also found that, within continents, trait proportions were similarly related to hydraulic and geomorphic variables, suggesting among-continent convergence in morphological and behavioural traits along similar environmental gradients. Such convergence in life-history traits along major environmental gradients has also been observed in stream fish communities between Australia and the United States (Olden \& Kennard, 2010) and between Mediterranean (i.e. Iberian Peninsula) and temperate western European fish communities (Logez, Pont \& Ferreira, 2010). Thus, even in the presence of 
evolutionary differences in species traits, communities may converge to some extent along the same environmental gradients in different continents or biogeographic regions (Lamouroux et al., 2002; Olden \& Kennard, 2010; Logez et al., 2010). However, additional case studies would be necessary to evaluate the relative roles of environmental filters (i.e. leading to convergence) and historical/evolutionary factors (i.e. leading to divergence) for the degree of convergence in species traits across biogeographic regions. These studies should also consider organism groups other than fish.

Some studies have simultaneously examined variation in community traits along geographical and multiple environmental gradients. For example, Logez et al. (in press) studied fish communities across Europe and found that the trait composition of these communities was mostly related to environmental factors (e.g. stream physical structure, temperature) and only secondarily affected by geographical location. Heino et al. (2007) found that environmental factors (e.g. stream size, $\mathrm{pH}$ ) were the most important determinants of functional feeding and habit trait structure of macroinvertebrate communities in boreal headwater streams. Despite that local environmental factors were important, also catchment variables and geographical location were influential for the trait structure of macroinvertebrate communities across Finland. Similar findings of the importance of different-scale variables on the trait structure of stream macroinvertebrate communities have also been obtained in the western part of the United States, where traits related to temperature and hydrologic regimes were strongly related to reach-scale, catchment-scale and the shared effects of reach, catchment and spatial variables (Poff et al., 2010). Moreover, Bêche \& Statzner (2009) found that both genus richness and trait richness varied significantly along local, catchment and geographical gradients, although the former measure of macroinvertebrate communities was more strongly associated with these abiotic gradients. The findings above suggest that the trait composition and trait richness are related to environmental filters acting at successive spatial scales and that also geographical location may affect independently trait composition across large 
geographical extents. By contrast, Statzner et al. (2004) suggested that the trait composition of stream macroinvertebrate communities varies only negligibly geographically and along natural environmental gradients across Europe. In this context, three interrelated aspect should be considered. (1) Trait variation may be neutral, i.e., it is related to differences in species pools that stems from the fact that species ranges are geographically limited. (2) Trait variation is niche driven, i.e., it is related to clear environmental differences among streams or among basins. Nichedriven processes may be further divided in (2a) natural differences in environmental conditions and (2b) anthropogenic differences in environmental conditions. Statzner et al. (2004) mainly considered case 2a, while Logez et al. (2010), Heino et al. (2007), Bêche \& Statzner (2009) and Poff et al. (2010) considered multiple possibilities. These studies also exemplify that traits are variably related to multiple abiotic gradients, which may stem from ecological (i.e. the underlying environmental template varies among studies), spatial (i.e. how large spatial extents are considered), practical (i.e. which traits have been used in the analysis) and analytical reasons (i.e. different methods are employed in different studies; see below).

A further important question related to the ecological, practical and statistical reasons, is the degree to which traits and taxa vary similarly along geographical gradients. This question is of great basic and applied interest, as traits should be relatively insensitive to geographical variation and taxa should be more geographically structured. If the geographical extent is larger than the geographic distributions of species, then one should expect that some species are restricted to certain parts of the study region (Poff \& Allan, 1995; Hoeinghaus et al., 2007; Pyron et al., 2011). By contrast, traits should be more strongly under environmental control than follow spatial structuring. Thus, if taxa whose distributions do not overlap possess similar traits, traits and taxa may not show similar geographical variation (Angermeier \& Winston, 1999; Hoeinghaus et al., 2007). A different situation may emerge when the distributions of most taxa are geographically wide in a region. Then, taxa and traits may show relatively similar geographical variation (Heino et 
al., 2007). Therefore, disregarding methodological reasons, the covariation between taxonomic and trait-based patterns among different regions may depend largely on the spatial extent of the study, differences in environmental conditions among regions and patterns in species distributions.

There may be geographical variation in the relative diversity of community traits. In the formerly glaciated high latitudes, trait variation is relatively high, almost as high as taxonomic variation of community composition along environmental gradients across and within ecoregions (Heino et al., 2007), among drainage basins (Schmera et al., unpublished) and within a drainage basin (Schmera et al., unpublished). Trait variability should be even higher in previously nonglaciated more southerly regions, but there much lower than taxonomic variability (due to much higher species richness in the more southerly regions). Thus, although the trait variability of stream communities can be expected to increase towards the equator, taxonomic variation is likely to do so even more rapidly, leading to weaker correspondence between traits and taxonomy at low latitudes than at high latitudes (cf. Béche \& Statzner, 2009 and Schmera et al., unpublished). This statement is speculative at the moment, however, and more studies spanning large geographical gradients are needed.

To synthesise, it appears that community traits are not as stable geographically and along natural environmental gradients as has been previously suggested (see Statzner et al., 2004). Although there is now evidence of convergence (i.e. similarity in trait-environment relationships) in traits along major environmental gradients among regions, other geographical patterns in community traits have been studied inadequately to allow emerging consensus (e.g. amongdrainage basins differences in traits). We thus strongly advocate further studies on community traits across large geographical extents, taking into account differences in biological and environmental characteristics among biogeographical regions and among drainage basins. 


\section{Patterns of species traits along environmental gradients within drainage basins}

Besides large-scale biogeographical factors, various environmental gradients shape the trait composition of ecological communities within drainage basins (Table 1). In fact, differences in environmental conditions within drainage basins can be comparable to among-region differences and, therefore, local environmental conditions may provide a strong trait filter. Although the species pool may be the same, ecological and evolutionary forces may have a clear legacy in affecting community traits in different parts of the stream network (e.g. 1st vs. 7 th order streams). Here, we will concentrate on three major environmental gradients within drainage basins, including the river longitudinal gradient, the hydrologic gradient and the temporal gradient. We by no means intend to argue that even when one of these major gradients is clearly dominant, other environmental factors are not affecting variation in the trait composition among sites. Rather, multiple environmental factors are typically active simultaneously, making it difficult to associate certain trait combinations to any single environmental factor both methodologically and ecologically. This difficulty pertains to the situation that there are often trade-offs between traits suited for living in a certain type of habitat (Townsend \& Hildrew, 1994; Usseglio-Polatera et al., 2000; Verberk et al., 2008).

There may be several traits or trait categories that facilitate the occurrence of an organism in certain habitat conditions, but a single species is unlikely to possess all of them (Townsend \& Hildrew, 1994; Finn \& Poff, 2005). As an example suggested by Finn \& Poff (2005), consider blackflies that possess traits that facilitate their occurrence in harsh high-altitude streams (e.g. high fecundity, fast seasonal development), but these organisms are also filter-feeders. The filter-feeding trait may indeed be selectively neutral in high-altitude streams, as its prevalence should increase with increases in stream size (Vannote et al., 1980; Allan \& Castillo, 2007). Similarly, in their review on trait-based studies on stream fishes, Frimpong and Angermeier (2010) 
emphasised the need for understanding trait syndromes that is a "suite of coevolved traits associated with an organism's performance" in a certain habitat. They gave an example, where an opportunistic life-history strategist species with small body size and short generation time may simultaneously evolve traits that enhance substrate spawning and benthic invertivory in shallow and hydrologically variable headwater stream habitat (Frimpong \& Angermeier, 2010). Clearly, because there are evolutionary trade-offs and ecological constraints among traits in their performance in complex stream environments, community-level trait patterns emerge from the interaction of individual species' trait combinations and environmental conditions. Thus, multiple trait filters that are acting simultaneously and between trait interactions may also lead to unexpected traitenvironment associations along the stream size gradient, decreasing the match between traits and environment (Dolédec \& Statzner, 2008; Verberk et al., 2008).

A classical example in stream ecology concerns the longitudinal changes in the functional feeding trait composition of benthic macroinvertebrate communities (Vannote et al., 1980; Allan \& Castillo, 2007). The River Continuum Concept (Vannote et al., 1980) predicts that headwater streams (orders 1-3) are dominated by shredders that benefit from the coarse organic material entering the stream from riparian vegetation. Co-dominants with shredders in headwaters are often collectors, which feed on fine particulate organic material. By contrast, although often present in low numbers, algae-grazing scrapers are limited by low light and predators perhaps by low availability of prey. In the mid-reaches (orders 4-6) of large rivers, scrapers increase in importance, being co-dominant with collectors, whereas shredders and predators are less important. In very large rivers (orders 7-12), collectors should attain a dominant position, whereas of the other feeding groups only predators are seemingly well represented there. Although such longitudinal changes in benthic communities have been observed in some river systems, particularly in temperate forested regions where the scheme was developed, the predicted match between longitudinal position and feeding traits in benthic communities has also been questioned 
(Winterbourn, Rounik \& Cowie, 1981; Statzner \& Higler, 1985; but see Grubaugh, Wallace \& Houston, 1996). Furthermore, it is now clear that the river longitudinal gradient is not only affecting the functional feeding trait composition, but also more localised environmental factors affect macroinvertebrate feeding modes and other traits (Richards et al., 1997; Heino et al., 2005; Statzner et al., 2005).

Differences in the strength of the trait-environment relationship can also be related to the strength of the underlying environmental gradient(s) and the number of environmental factors structuring communities. If there is a single main environmental gradient, then one may find strong trait-environment relationships. For example, studying fish traits along the longitudinal gradient in North America, Goldstein \& Meador (2004) found that large main-channel rivers were typified by planktivorous and herbivorous feeding strategies, migratory reproductive behaviour and broadcast spawning and lack of preference for substrate types. Their second main cluster of species included traits pertaining to invertivorous feeding strategy, simple nester reproductive behaviour and preferences for riffles with coarse substratum material (i.e. more likely to be found in smaller rivers and streams). These results suggest that variation in the trait composition of fish communities is related to large-scale differences in habitat factors along the river continuum.

A nested structure of trait composition may also be prevalent along the longitudinal gradient of large river systems. For example, Erös (2005) found that the life-history traits of fish in small streams formed a nested subset of those of fish in large rivers. Although headwater fish communities tended to have the smallest mean fecundity, maximum length and could be characterised by early maturation and by the least diverse life-history strategies (i.e. mainly opportunistic and opportunistic-periodic), large river fish communities also contained these features, and coupled with the life-history attributes in middle-sized rivers, these communities showed a diverse array of life-history attributes (i.e. opportunistic, periodic, equilibrium and their transitional stages). The main drivers of such longitudinal changes from small streams to middle- 
sized rivers are associated with the increase of environmental heterogeneity, where depth is clearly one of the most important factors (Schlosser, 1990). For large alluvial rivers, lateral environmental gradients also become important. Spatial and temporal hydrologic variability of the main channel and the different side arm structures probably provide the template for the formation of the most diverse trait combinations and functional diversity. Based on the research accumulated thus far, broad longitudinal patterns in the trait composition of stream fish communities can be summarised (Fig. 1), although this scheme should be further refined with more intensive research. Above findings about variation in community traits along the longitudinal gradient of temperate stream systems are supported by recent results from tropical regions, despite major climatic and faunal differences (e.g. Pease et al., 2012). However, local habitat filters may also limit the range of trait space that is occupied by species, and local-scale trait-habitat relationships should thus be accounted for when examining convergence in these relationships among larger geographical regions (Pease et al., 2012).

Hydrological variability has also been associated with variation in fish traits. Horwitz (1978) associated hydrological stability to fish taxonomic and trophic diversity, with diversity increasing with increasing hydrological stability. Poff \& Allan (1995) further found that fish communities at hydrologically variable sites were characterised by resource generalist species and more stable sites by a higher portion of more specialist species. Tedesco et al. (2008) also showed that the variation of West African tropical fish communities at the drainage basin scale can be partly explained by the match between life-history strategies and seasonality gradients in hydrologic conditions. Mims \& Olden (2012) found strong relationships between life history trait composition of fish communities and various measures of hydrologic variability, predictability and seasonality across the United States. Thus, hydrological variability is obviously one of the most important factors affecting trait variation in stream communities (see also Persat et al., 1994). 
Townsend, Doledec \& Scarsbrook (1997) also made an explicit attempt to relate organisms' traits to the hydrologic habitat template. Their habitat template comprised both spatial (i.e. hydraulic refugia) and temporal (i.e. stream bed movement) components. The latter of these components can also be understood as disturbance to the benthic organisms. Townsend et al. (1997) measured both components for a set of streams in a New Zealand drainage basin and tested for invertebrate trait-habitat associations across the streams. They found that more disturbed communities consisted of invertebrates with (1) small size, (2) high adult mobility, (3) habitat generalism, (4) streamlined or flattened body form and (5) major life stages occurring also outside streams. In a similar vein, Mellado Díaz et al. (2008) found that frequently disturbed sites in a Spanish drainage basin were characterised, for example, by invertebrates with (1) small size, (2) multivoltinism and (3) ovoviviparity, whereas more stable sites were typified, for example, by taxa with (1) large body size, (2) semivoltinism and (3) isolated eggs. Thus, it appears that increasing disturbance selects for small size and multivoltinism, which confer resilience to disturbance (Townsend et al., 1997; Mellado Díaz et al., 2008), and characteristics of body form and terrestrial life history stage, which confer resistance to disturbance (Townsend et al., 1997).

Mérigoux et al. (2001) similarly examined trait variation in juvenile fish, and found that a number of traits showed significant relationships with the spatio-temporal variability of neotropical floodplain creeks. For example, they found that size at maturity, mature oocyte diameter and relative body height decreased with increasing temporal variability, while size at maturity and mature oocyte diameter increased with increasing spatial variability. Mérigoux et al. (2001) also found that, in addition to spatio-temporal variability, average degree of habitat stability (i.e. mean water level and mean width of a creek) accounted for much of the variation in species traits. This study demonstrated not only that traits may vary strongly along spatio-temporal variability gradients, but also that average habitat conditions may be useful when examining trait-habitat associations (see also Verberk et al., 2008). 
A recent finding on stream fish communities has demonstrated that local environmental factors are not solely responsible for variation in community traits within a drainage basin. This is because dispersal-related factors, such as network distances among stream sites, can also significantly influence community traits (Erös et al., 2012). Furthermore, the relative roles of dispersal limitation and niche-based mechanisms may also show temporal variation. Although such temporal variability has now been demonstrated for fish communities in human-modified landscapes, further studies should be carried out in a variety of natural regional settings to confirm a broader applicability of these findings. It may well be that, similarly to variation in species composition in natural environmental settings (Heino \& Mykrä, 2008; Mykrä et al., 2011), also trait composition of communities varies both spatially and temporally in stream ecosystems.

Do traits and taxa vary similarly within a drainage basin? This question is again highly important, yet few studies have explicitly tested for the congruence between taxonomic and trait patterns within a drainage basin. Heino, Mykrä \& Kotanen (2008) found significant correlations between taxonomic diversity (i.e. richness, diversity and evenness) and trait diversity (i.e. richness, diversity and evenness) in a boreal drainage basin, attributing this finding to the effects of increasing stream size on both taxonomic diversity and trait diversity. Further evidence of relatively similar within-basin patterns comes from another study of a boreal river continuum (Heino et al., 2005) and from a set of alpine streams (Finn \& Poff, 2005). Furthermore, Schmera et al. (unpublished) recently showed that trait composition and richness patterns paralleled those of taxonomic patterns in each of three high latitude drainage basins. This finding is largely similar to that from a tropical drainage basin, where both fish taxonomic and functional composition changed along the stream size gradient (Pease et al., 2012). Based on rather limited evidence, it appears that taxonomic and trait patterns vary relatively similarly along major environmental gradients within drainage basins, which also suggests relatively high variability of traits along environmental gradients (see also Lamouroux et al., 2004). 


\section{Empirical and statistical approaches to understanding variation in community traits}

As suggested above, conclusions about trait-based community patterns among and within drainage basins and the responses of community traits to environmental factors may depend on the methods used to explore these patterns (for a summary of statistical approaches and methods used in traitbased community analyses, see Table 2). The outcome may be influenced by (i) the taxonomic resolution of taxa characterised by traits (e.g. species, genus, family or mixed), (ii) the number and (iii) types of traits considered, (iv) trait data quality and (v) how trait variation is quantified.

First, of aquatic organisms, the taxonomic resolution of the data tables used in traitbased analyses is a critical aspect in macroinvertebrate studies, where trait data tables usually show a mixed resolution of taxonomic levels. There are taxonomic groups which would be quite important both in quantifying diversity patterns and ecosystem processes (e.g. Chironomidae and Oligochaeta) in a variety of habitat types, but the lack of taxonomists and logistical constraints with their exact identification hinder their inclusion in biological and ecological data tables. Besides these constraints in taxonomic resolution, the lack of biological knowledge about the exact trait categories for many macroinvertebrate taxa may make this group quite problematic for trait-based comparisons. Consequently, public databases on traits of macroinvertebrates show a variety of taxonomic resolutions. Some databases contain mostly species level data but only for a limited number of traits (see Moog, 2005), various traits for species in one habitat type (see Gayraud et al., 2003) or present numerous traits for taxa with a mixed level of taxonomic resolution (see Tachet $e t$ al., 2010). Comparing results in trait patterns found in studies that are based on different taxonomic levels is highly difficult. Using exactly the same trait database, however, standardises the taxonomic resolution and makes inter-study comparisons more straightforward (Statzner \& Beche, 
2010). This is not say, however, that adherence to genus-level trait information should be the endpoint of research, and some researchers have argued for species-level trait data (Verberk et al., 2008).

Even if there were standardised data tables, the question of which traits should be considered in trait-based analyses is always challenging. This consideration may also influence among-region or among-habitat type comparisons. Theoretical considerations support the use of different traits depending on the purpose of the study (Petchey \& Gaston, 2006). For example, if the interest is on ecosystem function, one should concentrate on traits related to a specific function rather than associate the whole set of traits with such an ecosystem function. By contrast, if one is interested in overall trait variation for descriptive biodiversity studies, then as full as possible set of traits should be used. Although these examples show that different aspects of species traits can be considered, we agree with Petchey \& Gaston (2006) who suggested selecting all traits that are important for a research question and no traits that are irrelevant to it.

When traits relevant to a research question have been selected, one can focus on how these can be quantified for characterising ecological communities. As the data quality of traits varies considerably (e.g. fuzzy coding, measured variables, categorical variables, etc.), and because traits are often expressed by non-independent modality values, the transformation of taxon-specific traits (i.e. traits and modalities for a species) to community traits (i.e. the composition of traits and modalities of a community) is highly challenging. For example, if the habitat use of an animal is expressed by a fuzzy coding system and varies between 0 (no affinity) and 3 (high affinity) and the fecundity of the same animal by the number of eggs laid (that varies, say, between 50 and 20000), then it is clear that fecundity cause a greater degree of variation and thus should have a stronger impact on the data structure than habitat use. In this case, a good solution is the standardisation to the maximal trait value within a group of traits (Erös et al., 2008). This one and similar examples show that methodology should carefully be selected to avoid pitfalls in trait-based analyses. 
However, to our knowledge, no one has compared the patterns revealed by fuzzy-coded trait data, more defined trait data and more crudely resolved trait data. Obviously, there is an important niche for studies comparing differently-coded traits from the same data set to explore how data resolution influence inferences of trait patterns at various spatial and temporal scales.

Depending on the methodology and research question, the summarised output might be a multivariate point pattern (e.g. Usseglio-Polatera et al., 2000), an average distance value (e.g. Bady et al., 2005) or a measure of dispersion (e.g. Schmera, Erős \& Podani, 2009). All these measures of trait variation may be based on either abundance of presence-absence data. Hence, we discuss a few points regarding the use of abundance weight and the quantification of trait variation. Gayraud et al. (2003) found that abundance-weighted traits were less powerful than presenceabsence based traits in discriminating communities under different degrees of human impacts. Based on this finding, Statzner \& Beche (2010) advocated the use of presence-absence data of taxa for biomonitoring, because the sampling and the sorting of qualitative samples makes the assessment more cost-efficient. Interestingly, this conclusion is in disagreement with taxon-based analyses, which have shown that the abundance of taxa contributes to a better separation of communities in relation to environmental variation (Bradley \& Ormerod, 2002; Ostermiller \& Hawkins, 2004; Schmera \& Erős, 2011). Hence, the use of abundance and presence-absence data should be carefully re-evaluated when examining the responses of community traits to environmental variation.

The quantification of trait diversity is also strongly related to the use of abundance weight. Heino (2005) assigned macroinvertebrates into functional groups based on feeding and habit traits and then calculated functional diversity using the Shannon-Wiener diversity index. This index considers species abundance. In contrast, Bady et al. (2005) did not assign macroinvertebrates to groups, but applied the Rao's quadratic diversity index on their raw traitdatabase directly. This index uses abundance data and quantifies the average distance between two 
randomly selected individuals from the community (Ricotta, 2005). Other measures disregard abundances and count the number (Erös et al., 2009) or a standardised summarised distance between unique trait combinations (a unique trait combination is a group of taxa with identical traits; Schmera et al., 2009). Based on this short overview it is clear that differences in the mathematical background of diversity measures lead to the fact that these measures represent different aspects of trait variation. Consequently, general conclusions should be made carefully, because differences in findings among studies may reflect both ecological and methodological differences. A challenge for further studies is to disentangle the ecological and methodological components of variation in the patterns of trait diversity.

In the final stages of many research projects, the trait composition or trait diversity of numerous sites sampled is examined using exploration techniques or various test procedures (for the methods, see Legendre \& Legendre, 1998; Anderson et al., 2008; 2011). If the response matrix is of multivariate nature, indirect (unconstrained) ordinations reveal the main patterns of variation in the trait data structure, direct (constrained) ordinations try to display only the variation in the trait-data structure that can be explained by the constraining variables (e.g. environmental factors), and group tests examine whether a priori-defined groups are different from each other. If the response variable is of univariate nature (e.g. trait diversity) then traditional statistics with continuous (e.g. regression), categorical (e.g. ANOVA) or combinations of continuous and categorical predictors (e.g. ANCOVA) can be applied (Table 2). It has always to be born in mind, however, that multivariate and univariate analyses of patterns or among-group differences reveal different aspects of trait variation, and thus inter-study comparisons should acknowledge such potentially confounding factors with regard to ecological inferences.

The ecological inferences may also differ depending on the purpose of a trait study, which may determine what kinds of analyses are conducted. For example, researchers may be interested in (1) understanding the distribution of individual traits along environmental gradients 
(i.e. regression-based modelling); (2) variation in trait-based diversity (i.e. new area of research, where different indices are compared and modelled along environmental gradients); (3) trait-based community analyses to disentangle the relative importance of natural environmental and anthropogenic factors (i.e. mostly based on trait data tables and direct ordination methods); and (4) bioassessment of anthropogenic effects on stream ecosystems (i.e. individual traits are considered separately or as part of a composite multimetric index for evaluating ecosystem health).

To summarise, all practical, methodological and statistical aspects considered above should be taken into account in trait-based comparisons of ecological communities to filter out as much of the non-ecological differences among studies as possible. In fact, comparisons of the results among trait studies can easily lead to a similar debate that has been seen formerly between classification and gradient analyses, where the methodology used largely determined the outcome of the ecological inferences (CITATION).

\section{Where to go from here?}

There is evidence that the both the taxonomic and trait composition of stream communities varies along geographical and natural environmental gradients, although taxonomic characterisations of communities typically portray these gradients, especially geographical ones, more strongly. However, very few studies that have used the same set of analytical methods have examined variation in both trait and taxonomic composition of communities in different regions and both across and within drainage basins. There is thus need for further studies examining congruence between taxonomic and trait patterns in various geographical regions, environmental settings and organism groups (e.g. algae, macrophytes, invertebrates, fish). 
A further understudied aspect is temporal variation in the community traitenvironment relationships. It may well be that the temporal variability of stream systems does not allow strong development of trait-environment associations at the community level (see also Bêche $\&$ Resh, 2007). We thus believe that the relatively high amount of unexplained variance in studies of community traits may be related to the resilience of ecological communities to the temporal variability of stream ecosystems. This also means that snap-shot sampling of stream communities may not necessarily reflect the strongest associations among community traits and environmental conditions, as these associations are likely to vary on month-to-month and year-to-year temporal scales. It follows that it will be highly challenging to define strong community trait-environment associations using one-time samples from stream ecosystems.

\section{Stream macroecology would benefit greatly from more research on the following} topics. First, there should be a standard for examining community trait convergence and divergence along the same key environmental gradients among different regional entities, including biogeographic realms, ecoregions and drainage basins. The few studies that exist have pointed to the convergence of fish community traits (Lamouroux et al., 2002; Ibañez et al., 2009; Olden \& Kennard, 2010), but it is largely unknown to what extent other organism groups, including invertebrates, macrophytes and algae, show convergent or divergent trait patterns along the same key environmental gradients in different regions. Second, it is also unknown if these different organism groups show congruent trait patterns across drainage basins, and which factors may determine congruence, if it exists, among different organism groups across drainage basins. Somewhat related to this latter point is the degree to which taxonomic and trait-based diversity patterns differ among different regions. Thus far, studies have provided mixed evidence, with some stressing negligible among-region variation in traits (Statzner et al., 2004; Bonada et al., 2007), while others have suggested at least some among-region variation in traits (Heino et al., 2007; Poff et al., 2010). Further among-region studies based on various analytical approaches are needed to 
understand the degree to which traits show among-region variation similar to that of variation in the taxonomic composition of biotic communities.

Finally, congruence among taxonomic groups in community traits should also be directly addressed. Although congruence in taxonomic community patterns has been found to be weak among different taxonomic groups (reviewed by Heino, 2010), trait composition may vary more similarly among taxonomic groups across ecological gradients. This is because the environment may present a rather similar template for different organism groups (e.g. hydrologic regimes) and, therefore, variation in the trait composition of different taxonomic groups should be similar along ecological gradients. Alternatively, species in different taxonomic groups may perceive their habitat differently, responding to the habitat at different spatial and temporal scales (Resh et al., 1994). Thus, existing data sets where a number of taxonomic groups (e.g. algae, macrophytes, invertebrates and fish) have been sampled at the same set of sites could be used for answering to the question whether traits in different organism groups show similar or different responses to the habitat templet.

Although stream ecologists have been using trait variables rather routinely for understanding human impacts (Bonada et al., 2006), our knowledge of the spatial and temporal variability of community traits along natural environmental and geographical gradients at large spatial scales is insufficient at present. A challenge for large-scale stream ecology is thus to provide a holistic view of trait variation in multiple taxonomic groups, along geographical and environmental gradients (natural and anthropogenic) at different scales (biogeographic region, ecoregion, drainage basin).

\section{Acknowledgments}


The writing of this article was supported by grants from the Academy of Finland to Jani Heino. The work of Tibor Erős was supported by the János Bolyai Research Scholarship of the Hungarian Academy of sciences and by the OTKA PD 77684 research fund. We thank Wilco Verberk and an anonymous reviewer for comments on a previous version of this paper.

\section{References}

Allan, J.D. \& Castillo, M.M. (2007) Stream Ecology. Structure and Function of Running Waters. Springer.

Amoros, C. \& Petts, G.E. (Eds.) (1993) Hydrosystèmes Fluviaux. Masson, Paris.

Anderson, M. J., Crist, T. O., Chase, J. M., Vellend, M., Inouye, B. D., Freestone, A. L., Sanders, N. J., Cornell, H. V., Comita, L. S., Davies, K. F., Harrison, S. P., Kraft, N. J. B., Stegen, J. C. \& Swenson, N. G. (2011) Navigating the multiple meanings of $\beta$ diversity: a roadmap for the practicing ecologist. Ecology Letters, 14, 19-28.

Anderson, M.J., Gorley, R.N. \& Clarke, K.R. (2008) PERMANOVA+ for PRIMER. Guide to Software and Statistical Methods. PRIMER-E Ltd., Plymouth.

Angermeier, P.L. \& Winston, M.R. (1999) Characterizing fish community diversity across Virginia landscapes: prerequisite for conservation. Ecological Applications, 9, 335-349.

Bady, P., Doledec, S, Fesl, C, Gayraud, S., Bacchi, M. \& Schöll, F. (2005) Use of invertebrate traits for the biomonitoring of European large rivers: the effects of sampling effort on genus richness and functional diversity. Freshwater Biology, 50, 159-173.

Bailey, R.G. (2010) Ecosystem Geography. From Ecoregions to Sites. Springer. 
Bêche, L.A. \& Resh, V.H. (2007) Biological traits of benthic macroinvertebrates in California Mediterranean-climate streams: long-term annual variability and trait diversity patterns. Fundamental and Applied Limnology, 169, 1-23.

Bêche, L. \& Statzner, B. (2009) Richness gradients of stream invertebrates across the USA: taxonomy- and trait-based approaches. Biodiversity and Conservation, 18, 3909-3930.

Benda, L., Poff, N.L., Miller, D., Dunne, T., Reeves, G., Pess, G. \& Pollock, M. (2004) The network dynamics hypothesis: How channel networks structure riverine habitats. Bioscience, 54, 413-427.

Blackburn, T.M. \& Gaston, K.J. (2006) There's more to macroecology than meets the eye. Global Ecology and Biogeography, 15, 537-540.

Bonada, N. Doledec, S. \& Statzner, B. (2007) Taxonomic and biological trait differences of stream macroinvertebrate communities between Mediterranean and temperate regions: implications for future climatic scenarios. Global Change Biology, 13, 1658-1671.

Bonada, N., Prat., N., Resh, V.H. \& Statzner, B. (2006) Developments in aquatic insect biomonitoring: a comparative analysis of recent approaches. Annual Review of Entomology, 51, 495-523.

Bradley, D.C. \& Ormerod, S.J. (2002) Evaluating the precision of kick-sampling in upland streams for assessment of long-term change: the effect of sampling effort, habitat and rarity. Archiv für Hydrobiologie, 155, 199-221.

Brown, J.H. \& Lomolino, M.V. (1998) Biogeography. Sinauer. 
Charvet, E., Statzner, B., Usseglio-Polatera, P. \& Dumont, B. (2000) Traits of benthic macroinvertebrates in semi-natural French streams: and initial application to biomonitoring in Europe. Freshwater Biology, 43, 277-296.

Corkum, L. D. \& Ciborowski, J.H. (1988) Use of alternative classifications in studying broad-scale distributional patterns of lotic invertebrates. Journal of the North American Benthological Society, 7, 167-179.

Dolédec, S., Olivier, J.M. \& Statzner, B. (2000) Accurate description of the abundance of taxa and their biological traits in stream invertebrate communities: effects of taxonomic and spatial resolution. Archiv für Hydrobiologie, 148, 25-43.

Dolédec, S. \& Statzner, B. (2008) Invertebrate traits for the biomonitoring of large European rivers: an assessment of specific types of human impact. Freshwater Biology, 53, 617-634.

Ernst, R., Keller, A., Landburg, G, Grafe, T.U., Linsenmair, K.E. Rödel, M-O. \& Dziock, F. (2012) Common ancestry or environmental trait filters: Cross-continental comparisons of trait-habitat relationships in tropical anuran assemblages. Global Ecology and Biogeography, in press.

Erős, T. (2005) Life history diversification in the Middle Danubian fish fauna - a conservation perspective. Archiv für Hydrobiologie Supplement, 158, 289-304.

Erős, T., Heino, J., Schmera, D., Rask, M. (2009) Characterizing functional trait diversity and traitenvironment relationships in fish assemblages of boreal lakes. Freshwater Biology, $54,1788-1803$.

Erős, T., Schmera, D. \& Schick, R.S. (2011) Network thinking in riverscape conservation - a graph-based approach. Biological Conservation, 144, 184-192. 
Erős, T., Sály P., Takács P., Specziár A. \& Bíró P. (2012) Temporal variability in the spatial and environmental determinants of functional metacommunity organization - Stream fish in a human modified landscape. Freshwater Biology, in press.

Erős, T., Tóth, B., Sevcsik, A. \& Schmera, D. (2008) Comparison of fish assemblage diversity in natural and artificial rip-rap habitats in the littoral zone of a large river (River Danube, Hungary). International Review of Hydrobiology, 93, 88-105.

Finn, D.S. \& Poff, N.L. (2005) Variability and convergence in benthic communities along the longitudinal gradients of four physically similar Rocky Mountain streams. Freshwater Biology, 50, 243-261.

Frimpong, E.A. \& Angermeier, P.L. (2010) Trait-based approaches in the analysis of stream fish communities. American Fisheries Society Symposium, 73, 109-136.

Gasith, A. \& Resh, V.H. (1999) Streams in Mediterranean climate regions: abiotic influences and biotic responses to predictable seasonal events. Annual Review of Ecology and Systematics, 30, 51-81.

Gaston, K.J. \& Blackburn, T.M. (2000) Pattern and Process in Macroecology. Blackwell Science, Oxford.

Gayraud, S., Statzner, B., Bady, P., Haybach, A., Schöll, F., Usseglio-Polatera, P. \& Bacchi M. (2003) Invertebrate traits for the biomonitoring of large European rivers: an initial assessment of alternative metrics. Freshwater Biology, 48, 2045-2064.

Goldstein, R.M. \& Meador, M.R. (2004) Comparisons of fish species traits from small streams to large rivers. Transactions of the American Fisheries Society, 133, 971-983. 
Grubaugh, J.W., Wallace, J.B. \& Houston, E.S. (1996) Longitudinal changes of macroinvertebrate communities along an Appalachian stream continuum. Canadian Journal of Fisheries and Aquatic Sciences, 53, 896-909.

Heino, J. (2005) Functional biodiversity of macroinvertebrate assemblages along major ecological gradients of boreal headwater streams. Freshwater Biology, 50, 1578-1587.

Heino, J. (2010) Are indicator groups and cross-taxon congruence useful for predicting biodiversity in aquatic ecosystems? Ecological Indicators, 10, 112-117.

Heino, J. (2011) A macroecological perspective of diversity patterns in the freshwater realm. Freshwater Biology, 56, 1703-1722.

Heino, J. \& Mykrä, H. (2008) Control of stream insects assemblages: roles of spatial configuration and local environmental variables. Ecological Entomology, 33, 614-622.

Heino, J., Mykrä, H. \& Kotanen, J. (2008) Weak relationships between landscape characteristics and multiple facets of stream macroinvertebrate biodiversity in a boreal drainage basin. Landscape Ecology, 23, 417-426.

Heino, J., Mykrä, H., Kotanen, J. \& Muotka, T. (2007) Ecological filters and variability in stream macroinvertebrate communities: do taxonomic and functional structure follow the same path? Ecography, 30, 217-230.

Heino, J., Parviainen, J., Paavola, R., Jehle, M., Louhi, P. \& Muotka, T. (2005) Characterizing macroinvertebrate assemblage structure in relation to stream size and tributary position. Hydrobiologia, 539, 121-130. 
Hoeinghaus, D.J., Winemiller, K.O. \& Birnbaum, J.S. (2007) Local and regional determinants of stream fish assemblage structure: inferences based on taxonomic vs. functional groups. Journal of Biogeography, 34, 324-338.

Horwitz, R.J. (1978) Temporal variability patterns and the distributional patterns of stream fishes. Ecological Monographs, 48, 307-321.

Hugueny, H., Oberdorff, T. \& Tedesco, P.A. (2010) Community ecology of river fishes: a large scale perspective. American Fisheries Society Symposium, 73, 29-62.

Hynes, H.B.N. (1970) The Ecology of Running Waters. Toronto University Press.

Ibañez, C., J. Belliard, J., Hughes, R.M., Irz, P., Kamdem-Toham, A., Lamouroux, N., P. A. Tedesco, P.A. \& Oberdorff, T. (2009) Convergence of temperate and tropical stream fish assemblages. Ecography, 32, 658-670.

Illies, J. \& Botosaneanu, L. (1963) Problémes et méthodes de la classification et de la zonation écologique des eaux courantes, considerées surtout du point de vue faunistique. Mitteilungen Internationalen Vereinigung fürTheoretische und Angewandte Limnologie, 12, 1-57

Jacquemin, S.J. \& Pyron, M. (2011) Impact of past glaciations events on contemporary fish assemblages of the Ohio River basin. Journal of Biogeography, 38, 982-991.

Lamouroux, N., Doldec, S. \& Gayraud, S. (2004) Biological traits of stream macroinvertebrate assemblages: effect of microhabitat, reach and basin filters. Journal of the North American Benthological Society, 23, 449-466.

Lamouroux, N., Poff, N.L. \& Angermeier, P.L. (2002) Intercontinental convergence of stream fish community traits along geomorphic and hydraulic gradients. Ecology, 83, 1792-1807. 
Legendre, P. \& Legendre, L. (1998) Numerical Ecology. Elsevier, Amsterdam.

Logez, M., Bady, P., Melcher, A. \& Pont, D. (in press) A continental-scale analysis of fish assemblage functional structure in European rivers. Ecography.

Logez, M., Pont, D. \& Ferreira, M.T. (2010) Do Iberian and European fish faunas exhibit convergent functional structure along environmental gradients? Journal of the North American Benthological Society, 29, 1310-1323.

McGill, B.J., Enquist, B.J., Weiher, E. \& Westoby, M. (2006) Rebuilding community ecology from functional traits. Trends in Ecology and Evolution, 21, 178-185.

Mellado Díaz, A., Suárez Alonso, M.L. \& Vidal-Abarca Gutiérrez, M.R. (2008) Biological traits of stream macroinvertebrates from a semi-arid catchment: pattern along complex environmental gradients. Freshwater Biology, 53, 1-21.

Menezes, S. Baird, D.J., Soares, A.M.V.M. (2010) Beyond taxonomy: a review of macroinvertebrate trait-based community descriptors as tools for freshwater biomonitoring. Journal of Applied Ecology, 47, 711-719.

Mérigoux, S., Dolédec, A. \& Statzner, B. (2001) Species traits in relation to habitat variability and state: neotropical juvenile fish in floodplain creeks. Freshwater Biology, 46, 12511267.

Minshall, G.W. (1988) Stream ecosystem theory: a global perspective. Journal of the North American Benthological Society, 7, 26-288.

Minshall, G. W., Petersen, R. C., Cummins, K.W., Bott, T.L., Sedell, J.R., Cushing, C.E. \& Vannote, R.L. (1983) Interbiome comparison of stream ecosystem dynamics. Ecological Monographs, 53, 1-25. 
Mims, M.C. \& Olden, J.D. (2012) Life history theory predicts fish assemblage response to hydrologic regimes. Ecology, 93, 35-45.

Mims, M.C., Olden, J.D., Shattuck, Z.R. \& Poff, N.L. (2010) Life history trait diversity of native freshwater fishes in North America. Ecology of Freshwater Fish, 19, 390-400.

Moog, O. (1995) Fauna Aquatica Austriaca. Lieferung Mai/95. Wasserwirtschaftkataster, Bundesminsterium für Land- und Forstwirtschaft, Wien.

Mykrä, H., Heino, J., Oksanen, J. \& Muotka, T. (2011) The stability-diversity relationship in stream macroinvertebrates: influences of sampling effects and habitat complexity. Freshwater Biology, 56, 1122-1132.

Oberdorff, T., Tedesco, P., Hugueny, B., Leprieur, F., Beauchard, O., Brosse, S. \& Dürr, H. (2011) Global and regional patterns of riverine fish species richness: a review. International Journal of Ecology, 2011, Article ID 967631.

Olden, J.D. \& Kennard, M.J. (2010) Intercontinental comparison of fish life history strategies along a gradient of hydrologic variability. American Fisheries Society Symposium, 73, 83107.

Olden, J.D., Kennard, M.J., Leprieur, F., Tedesco, P.A., Winemiller, K.O. \& García-Berthou, E. (2010) Conservation biogeography of freshwater fishes: recent progress and future challenges. Diversity and Distributions, 16, 496-513.

Ostermiller, J.D \& Hawkins, C.P. (2004) Effects of sampling error on bioassessment of stream ecosystems: application to RIVPACS-type models. Journal of the North American Benthological Society, 23, 363-382. 
Pease, A.A., González-Díaz, A.A, Rodiles-Hernández, R. \& Winemiller, K.O. (2012) Functional diversity and trait-environment relationships of stream fish assemblages in a large tropical catchment. Freshwater Biology, 57, 1060-1075.

Persat, H., Olivier, J.-M. \& Pont, D. (1994) Theoretical habitat templets, species traits, and species richness: fish in the Upper Rhône River and its floodplain. Freshwater Biology, 31, 439-454.

Petchey, O.L. \& Gaston, K.J. (2006) Functional diversity: back to basics and looking forward. Ecology Letters, 9, 741-758.

Poff, N.L. (1996) A hydrogeography of unregulated streams in the United States and an examination of scale-dependence in some hydrological descriptors. Freshwater Biology, 36, 71-91.

Poff, N.L. (1997) Landscape filters and species traits: towards a mechanistic understanding and prediction in stream ecology. Journal of the North American Benthological Society, 16, 391-409.

Poff, N.L. \& Allan, J.D. (1995) Functional organization of stream fish assemblages in relation to hydrological variability. Ecology, 76, 606-627.

Poff, N.L., Pyne, M.I., Bledsoe, B.P., Cuhaciyan, C.C. \& Carlisle, D.M. (2010) Developing linkages between species traits and multiscaled environmental variation to explore vulnerability of stream benthic communities to climate change. Journal of the North American Benthological Society, 29, 1441-1458.

Poff, N.L. \& Ward, J.V. (1990) Physical habitat template of lotic systems: recovery in the context of historical pattern of spatiotemporal heterogeneity. Environmental Management, 14, $629-645$. 
Pyron, M., Williams, L., Beugly, J. \& Jacquemin, S.J. (2011) The role of trait-based approaches in understanding stream fish assemblages. Freshwater Biology, 56, 1579-1592.

Resh, V.H., Hildrew, A.G., Statzner, B. \& Townsend, C.R. (1994) Theoretical habitat templets, species traits, and species richness: a synthesis of long-term ecological research on the Upper Rhône River in the context of concurrently developed ecological theory. Freshwater Biology, 31, 539-554.

Richards, C., Haro, R.J., Johnson, L.B. \& Host, G.E. (1997) Catchment and reach-scale properties as indicators of macroinvertebrate species traits. Freshwater Biology, 37, 219-230.

Ricotta, C. (2005) A note on functional diversity measures. Basic and Applied Ecology, 6, 479-486.

Ross, H.H. (1963) Stream communities and terrestrial biomes. Archiv für Hydrobiologie, 59, 235242.

Schlosser, (1990)

Schluter, D. (1986) Tests for similarity and convergence of finch communities. Ecology, 67, 10731085.

Schmera, D., \& Erős, T. (2011) The role of sampling effort, taxonomical resolution and abundance weight in multivariate comparison of stream dwelling caddisfly assemblages collected from riffle and pool habitats. Ecological Indicators, 11, 230-239.

Schmera, D., Erős, T. \& Podani, J. (2009) A measure for assessing functional diversity in ecological communities. Aquatic Ecology, 43, 157-167.

Shipley et al. (2006) Science 314: 812

Southwood, T.R.E. (1977) Habitat: the templet for ecological strategies? Journal of Animal Ecology, 46, 337-365. 
Statzner, B. \& Beche, L. (2010) Can biological invertebrate traits resolve effects of multiple stressors on running water ecosystems? Freshwater Biology, 55, 80-119.

Statzner, B., Bis, B., Doledec, S. \& Usseglio-Polatera, P. (2001) Perspectives for biomonitoring at large spatial scales: a unified measure for the functional composition of invertebrate communities in European running waters. Basic and Applied Ecology, 2, 73-85.

Statzner, B., Bonada, N. \& Doledec, S. (2008) Biological attributes discriminating invasive from native European stream macroinvertebrates. Biological invasions, 10, 517-530.

Statzner, B., Doledec, S. \& Hugueny, B. (2004) Biological trait composition of European stream invertebrate communities: assessing the effects of various trait filter types. Ecography, 27, 470-488.

Statzner, B., Bady, P., Doledec, S. \& Schöll, F. (2005) Invertebrate traits for the biomonitoring of large European rivers: an initial assessment of trait patterns in least impacted river reaches. Freshwater Biology, 50, 2136-2161.

Statzner, B. \& Higler, B. (1985) Questions and comments on the river continuum concept. Canadian Journal of Fisheries and Aquatic Sciences, 42, 1038-1044.

Statzner, B., Hildrew, A.G. \& Resh, V.H. (2001) Species traits and environmental constraints: entomological research and the history of ecological theory. Annual Review of Entomology, 46, 291-316.

Tachet, H., Richoux P., Bournaud, M. \& Usseglio-Polatera P. (2010) Invertébrés d'eau Douce: Systematique, Biologie, Ecologie. CNRS Editions. 
Tedesco, P., Hugueny, B., Oberdorff, T., Durr, H.H., Merigoux, S. \& de Merona, B. (2008) River hydrological seasonality influences life history strategies of tropical riverine fishes. Oecologia, 156, 691-702.

Tonn, W.M. (1990) Climate change and fish communities: a conceptual framework. Transactions of the American Fisheries Society, 133, 971-983.

Townsend, C.R., Doledec, S. \& Scarsbrook, M.R. (1997) Species traits in relation to temporal and spatial heterogeneity in streams: a test of habitat templet theory. Freshwater Biology, 37, 367-387.

Townsend, C.R. \& Hildrew, A.G. (1994) Species traits in relation to a habitat templet for rover systems. Freshwater Biology, 31, 265-275.

Usseglio-Polatera, P., Bournaud, M. Richoux, M., \& Tachet, H. (2000) Biological and ecological traits of benthic freshwater macroinvertebrates: relationships and definitions of groups with similar traits. Freshwater Biology, 43, 175-205.

Vannote, R.L. Minshall, G.W., Cummins, K.W., Sedell, J.R. \& Cushing, C.E. (1980) The river continuum concept. Canadian Journal of Fisheries and Aquatic Sciences, 37, 130137.

Verberk, W.C.E.P., Siepel, H. \& Esselink, H. (2008) Life-history strategies in freshwater macroinvertebrates. Freshwater Biology, 53, 1722-1738.

Verberk, W.C.E.P, van der Velde, G. \& Esselink, H. (2010) Explaining abundance-occupancy relationships in specialists and generalists: a case study on aquatic macroinvertebrates in standing waters. Journal of Animal Ecology, 79, 589-601. 
Webb, C.T., Hoeting, J.A., Ames, G.M., Pyne, M.I. \& Poff, N.L. (2010) A structured and dynamic framework to advance traits-based theory and prediction in ecology. Ecology Letters, 13, 267-283.

Winemiller, K.O. (1992) Life-history strategies and the effectiveness of sexual selection. Oikos, 63, 318-327.

Winemiller, K.O. (2005) Life history strategies, population regulation, and implications for fisheries management. Canadian Journal of Fisheries and Aquatic Sciences, 52, 875.

Winemiller, K.O. \& Rose, K.A. (1992) Patterns of life-history diversification in North American fishes: implications for population regulation. Canadian Journal of Fisheries and Aquatic Sciences, 49, 2196-2218.

Winterbourn, M.J., Rounick, J.S. \& Cowie, B. (1981) Are New Zealand stream ecosystems really different? New Zealand Journal of Marine and Freshwater Research, 15, 321-328.

Witman, J.D. \& Roy, K. (eds) (2009) Marine Macroecology. Chicago University Press, Chicago.

Table 1. Macroecological approaches to study variation in community traits at different spatial scales.

\begin{tabular}{|l|l|l|}
\hline Approach & Aim & Reference \\
\hline $\begin{array}{l}\text { Across-watersheds } \\
\text { patterns }\end{array}$ & $\begin{array}{l}\text { To examine overall trait variation across } \\
\text { regions (i.e. regional grain sizes) }\end{array}$ & Mims et al. (2010) \\
\hline $\begin{array}{l}\text { Among-region patterns: } \\
\text { mean differences }\end{array}$ & $\begin{array}{l}\text { To examine trait variation of local } \\
\text { communities among regions }\end{array}$ & $\begin{array}{l}\text { Bonada } \text { et al. (2007), } \\
\text { Heino et al. (2007) }\end{array}$ \\
\hline
\end{tabular}




\begin{tabular}{|l|l|l|}
\hline $\begin{array}{l}\text { Among-region patterns: } \\
\text { community convergence }\end{array}$ & $\begin{array}{l}\text { To examine trait variation of local } \\
\text { communities along similar environmental } \\
\text { gradients in different geographic regions and } \\
\text { compare trait responses among regions }\end{array}$ & $\begin{array}{l}\text { Lamouroux } \text { et al. } \\
\text { (2002), Olden \& } \\
\text { Kennard (2010) }\end{array}$ \\
\hline $\begin{array}{l}\text { Across-communities } \\
\text { patterns: large extents }\end{array}$ & $\begin{array}{l}\text { To examine trait variation across local } \\
\text { communities along geographical and } \\
\text { environmental gradients at broad } \\
\text { geographical extents }\end{array}$ & $\begin{array}{l}\text { Heino } \text { et al. } \text { (2007), } \\
\text { Hoeinghaus } \text { et al. } \\
\text { (2007) }\end{array}$ \\
\hline $\begin{array}{l}\text { Across-communities } \\
\text { patterns: within } \\
\text { watershed extents }\end{array}$ & $\begin{array}{l}\text { To examine trait variation across local } \\
\text { communities within a drainage basin, e.g., } \\
\text { along river longitudinal and other } \\
\text { environmental gradients }\end{array}$ & $\begin{array}{l}\text { Townsend } \text { et al. } \text { (2003), } \\
\text { Eros } \text { et al. (2012) }\end{array}$ \\
\hline $\begin{array}{l}\text { Across habitat types: } \\
\text { within watershed extents }\end{array}$ & $\begin{array}{l}\text { To examine differences in trait variation of } \\
\text { generalist and specialist species from the } \\
\text { perspective of the occupancy-abundance } \\
\text { relationships }\end{array}$ & Verberk et al. (2010) \\
\hline
\end{tabular}

Table 2. Main statistical methods typically used to analyse variation in community traits. Reference refers to articles that have applied a method mentioned in the table. For further information about the methods, see Legendre \& Legendre (1998) and Anderson et al. (2011).

\begin{tabular}{|l|l|l|}
\hline Method & Aim & Reference \\
\hline $\begin{array}{l}\text { (a) Trait composition } \\
\text { Indirect ordination } \\
\text { analysis }\end{array}$ & $\begin{array}{l}\text { To explore patterns in trait composition } \\
\text { across a set of watersheds or a set of sites. }\end{array}$ & $\begin{array}{l}\text { Mims et al. (2010), } \\
\text { Pease } \text { et al. (2012) }\end{array}$ \\
\hline
\end{tabular}




\begin{tabular}{|c|c|c|}
\hline $\begin{array}{l}(\mathrm{CA}, \mathrm{FCA}, \mathrm{CoA}, \mathrm{PCA}, \\
\mathrm{PCoA})\end{array}$ & & \\
\hline $\begin{array}{l}\text { Direct ordination } \\
\text { analysis } \\
\text { (CCA, RDA, CAP, } \\
\text { RLQ) }\end{array}$ & $\begin{array}{l}\text { To relate variation in community traits to } \\
\text { geographical, catchment and local } \\
\text { environmental variables across a set of sites. } \\
\text { Also used for partitioning variation in trait } \\
\text { composition among different variable sets. }\end{array}$ & $\begin{array}{l}\text { Heino et al. (2007), Poff } \\
\text { et al. (2010) }\end{array}$ \\
\hline $\begin{array}{l}\text { Group tests } \\
\text { (CAP, PERMDISP, } \\
\text { MRPP) }\end{array}$ & $\begin{array}{l}\text { To test for differences in trait composition } \\
\text { among two or more sets of sites. Also used } \\
\text { for testing "average" differences in trait } \\
\text { composition among categories (CAP, MRPP) } \\
\text { or "heterogeneity" differences in trait } \\
\text { composition among categories (PERMDISP) }\end{array}$ & $\begin{array}{l}\text { Schmera et al. } \\
\text { (unpublished) }\end{array}$ \\
\hline $\begin{array}{l}\text { Tests related to life- } \\
\text { history strategy }\end{array}$ & $\begin{array}{l}\text { To assign species to strategies based on the } \\
\text { traits possessed and use basic statistics } \\
\text { (GLM, ANOVA) to test for differences in } \\
\text { abundance. }\end{array}$ & Verberk et al. (2008) \\
\hline Maximum Entropy & $\begin{array}{l}\text { To infer species abundances, using } \\
\text { information about species traits to find the } \\
\text { species abundances that maximize a measure } \\
\text { of entropy. }\end{array}$ & Shipley et al. (2006) \\
\hline (b) Trait diversity & & \\
\hline $\begin{array}{l}\text { Regressive methods } \\
\text { (Regression, GLM) }\end{array}$ & $\begin{array}{l}\text { To relate variation in trait diversity to } \\
\text { environmental gradients. }\end{array}$ & $\begin{array}{l}\text { Heino (2005), Schmera } \\
\text { et al. (unpublished) }\end{array}$ \\
\hline $\begin{array}{l}\text { Difference between } \\
\text { categories } \\
\text { (ANOVA, ANCOVA) }\end{array}$ & $\begin{array}{l}\text { To examine differences in trait diversity } \\
\text { among categories (e.g. regions). Also used to } \\
\text { examine the effects of a categorical variable, } \\
\text { a continuous variable and their interaction on } \\
\text { trait diversity or trait proportions. }\end{array}$ & Lamouroux et al. (2002) \\
\hline
\end{tabular}


Abbreviations: $\mathrm{CA}=$ correspondence analysis; FCA = fuzzy correspondence analysis; $\mathrm{CoA}=$ coinertia analysis; $\mathrm{PCA}=$ principal components analysis; $\mathrm{PCoA}=$ principal coordinates analysis; $\mathrm{CCA}=$ canonical correspondence analysis; $\mathrm{RDA}=$ redundancy analysis, $\mathrm{CAP}=$ canonical analysis of principal coordinates, PERMDISP = permutational analysis of multivariate dispersions, MRPP $=$ multi-response permutation procedure; GLM = general linear models; ANOVA = analysis of variance; ANCOVA = analysis of covariance. 


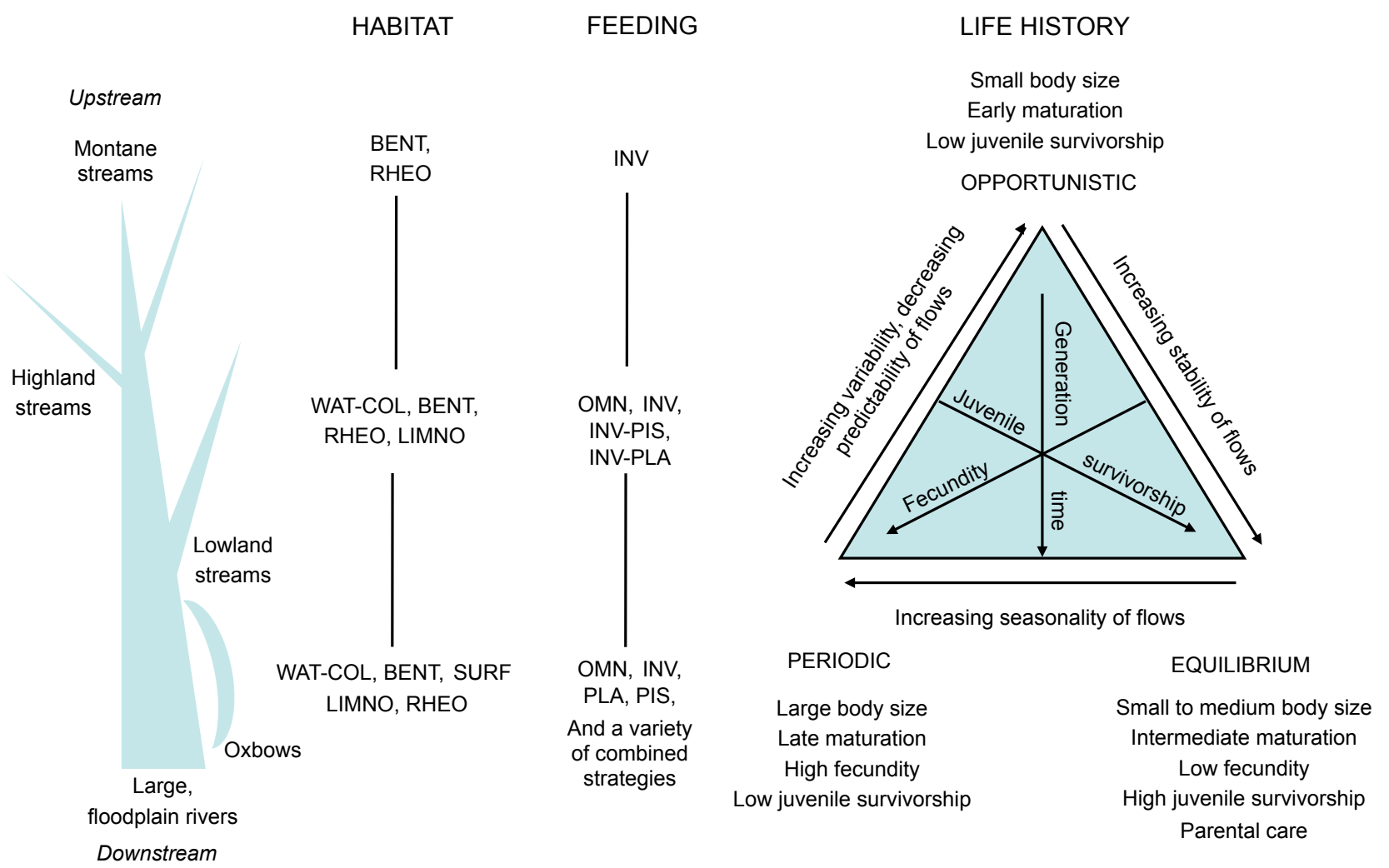

Fig. 1. Schematic trait-based patterns of fish communities along the longitudinal profile of a large river system considering the three most influential traits used in the literature (i.e., habitat, feeding and life history). The upstream fish communities can be characterised by the least diverse trait combinations and contain mostly benthic, rheophylic, invertivore species, with the opportunistic life history strategy. Such a trait composition fits well to the physical environment of upstream habitats. When proceeding downstream, the diversity of trait combinations increases for any of the traits considered. In fact, upstream trait composition may form a nested subset of downstream ones, but the relative importance of traits may differ largely between habitats (e.g. oxbows, main channel) and hydrologic regimes. The life history continuum model shown is adapted from Winemiller (1992, 2005) and Winemiller \& Rose (1992) following Mims \& Olden (2012). Trait abbreviations in the "habitat trait group" are as follows: BENT = benthic; WAT-COL = water column; SURF = surface; RHEO = rheophilic; LIMN, limnophilic. Trait abbreviations in the "feeding trait group" are 
as follows: $\mathrm{INV}=$ invertivore; $\mathrm{OMN}=$ omnivore; $\mathrm{PIS}=$ piscivore; $\mathrm{PLA}=$ planktivore, and species showing intermediate feeding strategy (e.g. INV-PIS). 